Marquette University

e-Publications@Marquette

Biological Sciences Faculty Research and

Publications

Biological Sciences, Department of

$1-29-2016$

\title{
Lianas Suppress Seedling Growth and Survival of 14 Tree Species in a Panamanian Tropical Forest
}

Laura Martinez Izquierdo

Marquette University

Maria M. Garcia

Marquette University

Jennifer S. Powers

University of Minnesota

Stefan A. Schnitzer

Marquette University, stefan.schnitzer@marquette.edu

Follow this and additional works at: https://epublications.marquette.edu/bio_fac

Part of the Biology Commons

\section{Recommended Citation}

Martinez Izquierdo, Laura; Garcia, Maria M.; Powers, Jennifer S.; and Schnitzer, Stefan A., "Lianas Suppress Seedling Growth and Survival of 14 Tree Species in a Panamanian Tropical Forest" (2016).

Biological Sciences Faculty Research and Publications. 683.

https://epublications.marquette.edu/bio_fac/683 


\title{
Lianas suppress seedling growth and survival of 14 tree species in a Panamanian tropical forest
}

\author{
Laura Martínez-Izquierdo, ${ }^{1}$ María M. García, ${ }^{1}$ Jennifer S. Powers,,${ }^{2,3}$ and Stefan A. Schnitzer ${ }^{1,3,4}$ \\ ${ }^{1}$ Department of Biological Sciences, Marquette University, P.O. Box 1881, Milwaukee, Wisconsin 53201, USA \\ ${ }^{2}$ Departments of Ecology, Evolution and Behavior and Plant Biology, University of Minnesota 1987 Upper Buford Circle, \\ St. Paul, Minnesota 55108, USA \\ ${ }^{3}$ Smithsonian Tropical Research Institute, Apartado Postal 0843-03092, Balboa, República de Panamá
}

\begin{abstract}
Lianas are a common plant growth form in tropical forests, where they compete intensely with trees, decreasing tree recruitment, growth, and survival. If the detrimental effects of lianas vary significantly with tree species identity, as is often assumed, then lianas may influence tree species diversity and community composition. Furthermore, recent studies have shown that liana abundance and biomass are increasing relative to trees in neotropical forests, which will likely magnify the detrimental effects of lianas and may ultimately alter tree species diversity, relative abundances, and community composition. Few studies, however, have tested the responses of multiple tree species to the presence of lianas in robust, well-replicated experiments. We tested the hypotheses that lianas reduce tree seedling growth and survival, and that the effect of lianas varies with tree species identity. We used a large-scale liana removal experiment in Central Panama in which we planted 14 replicate seedlings of 14 different tree species that varied in shade tolerance in each of $1680 \times 80 \mathrm{~m}$ plots (eight liana-removal and eight unmanipulated controls; 3136 total seedlings). Over a nearly two-yr period, we found that tree seedlings survived $75 \%$ more, grew 300\% taller, and had twice the aboveground biomass in liana-removal plots than seedlings in control plots, consistent with strong competition between lianas and tree seedlings. There were no significant differences in the response of tree species to liana competition (i.e., there was no species by treatment interaction), indicating that lianas had a similar negative effect on all 14 tree species. Furthermore, the effect of lianas did not vary with tree species shade tolerance classification, suggesting that the liana effect was not solely based on light. Based on these findings, recently observed increases in liana abundance in neotropical forests will substantially reduce tree regeneration, but will not significantly alter tropical tree species diversity, relative abundance, or community composition.
\end{abstract}

Keywords: Barro Colorado Island; community ecology; Gigante Peninsula; liana cutting; Panama; tropical plant competition.

\section{INTRODUCTION}

Tropical forests comprise $7 \%$ of the earth's land surface, but they contain more than half of the world's species and are responsible for $>30 \%$ of aboveground terrestrial productivity and carbon storage (Gibbs et al. 2007, Bonan 2008, Beer et al. 2010, Pan et al. 2011). Historically, the major threats to tropical forests have been logging, mining, and farming, which have greatly reduced the extent of tropical forests worldwide (Wright 2005, 2010, Laurance et al. 2009). Mature tropical forests that escaped the direct effects of human activity, however, may be experiencing indirect effects of global change. One of the prominent large-scale structural changes occurring in many neotropical forests is the

\footnotetext{
Manuscript received 25 November 2014; revised 7 July 2015; accepted 9 July 2015. Corresponding Editor: M. Uriarte.

${ }^{4}$ E-mail: S1@marquette.edu
}

increase in the density, biomass, and productivity of lianas (Phillips et al. 2002, Schnitzer and Bongers 2011). There is evidence of liana increases in forests in Bolivia, Brazil, Costa Rica, French Guiana, Panama, and the southeastern United States (Schnitzer 2015). Combined, these studies demonstrate that, relative to trees, lianas are increasing in seedling and adult stem density, basal area, and productivity in neotropical forests, which is likely to increase the competitive effects of lianas on trees (Schnitzer et al. 2011).

Strong competition from lianas may structure tree communities by altering tree species diversity, community composition, and the relative abundance of tree species. Lianas compete intensely with trees for above- and belowground resources, decreasing recruitment, growth, survival, and reproduction of trees throughout the forest (Carsten et al. 2002, Schnitzer and Bongers 2002, Kainer et al. 2006, Kurzel et al. 2006, Peña-Claros et al. 2008, van der Heijden and 
Phillips 2009, Schnitzer and Carson 2010, Wright et al. 2015). However, lianas may not affect all trees equally. Lianas appear to have a strong negative effect on shade-tolerant trees, but perhaps a relatively weak effect on select pioneer trees. For example, some gapspecialist trees, particularly those that grow rapidly, have slender and flexible trunks with very few branches (e.g., Cecropia spp.), appear to suffer relatively low liana infestation (Putz 1984, Clark and Clark 1990), and regenerate readily in treefall gaps (Schnitzer et al. 2000, Schnitzer and Carson 2010). However, the vast majority of the tree species in tropical forests lack these liana-avoiding characteristics, and they may commonly suffer from intense liana competition (Schnitzer et al. 2000, 2005, van der Heijden et al. 2008, Ingwell et al. 2010, Schnitzer and Carson 2010). If the strength of liana competition varies with species identity beyond the select gap-specialist vs. shade-tolerant tree dichotomy, then lianas may influence tree community composition by altering the competitive ability of tree species (Schnitzer and Bongers 2002). Furthermore, the effects of lianas on tree community composition will likely intensify as liana abundance increases in neotropical forests (Schnitzer 2015). However, whether the vast majority of tree species, beyond a small group of select gap-specialists, have a species-specific response to lianas, remains poorly understood (van der Heijden et al. 2008, Ingwell et al. 2010, Álvarez-Cansino et al. 2015, Wright et al. 2015).

Several studies have suggested that the impact of lianas on tree species, particularly at the seedling stage, varies with tree species identity, and thus lianas can change tropical forest community composition by changing recruitment dynamics among tree species (e.g., Chittibabu and Parthasarathy 2001, Pérez-Salicrup 2001, Wright et al. 2015). For example, in a lowland liana forest in Bolivia, experimental liana removal resulted in significantly higher seedling growth for Astronium fraxinifolium compared to Clarisia ilicifolia, suggesting that lianas hinder the seedling growth of some tree species more than others (Pérez-Salicrup 2001). Similar results were found by Toledo-Aceves and Swaine (2008) in a tropical moist semi-deciduous forest in Ghana, where the liana Acacia kamerunensis had a greater negative impact on the seedling growth of the tree Khaya anthotheca compared to two other tree species, indicating that lianas could modify tree species' capacity to establish and regenerate. Likewise, using a target tree-based liana removal in central Panama, Wright et al. (2015) reported that lianas significantly reduced tree seedling growth, and this effect was strongest during the dry season for one of the three tree study species. By contrast, other experimental liana removal studies have reported that lianas suppressed all tree seedlings/saplings, regardless of tree species identity (e.g., Schnitzer et al. 2005). Until now, however, highly replicated experimental approaches to test the responses of seedlings of multiple tree species to liana competition in tropical forests have been lacking.
Previous studies either examined very few tree species, a relatively small number of replicates per treatment, or used a small-scale liana removal manipulation (PérezSalicrup 2001, Schnitzer et al. 2005, Toledo-Aceves and Swaine 2008, Wright et al. 2015), thereby lacking the ability to determine whether the effects of lianas vary broadly with tree species identity.

We investigated the effect of lianas on the survival and growth of seedlings of 14 tropical tree species in a seasonal moist tropical forest in Central Panama. We transplanted 14 replicate seedlings of each species into the center of large areas $(80 \times 80 \mathrm{~m})$ of forest in which we had recently removed all lianas and into unmanipulated control plots where lianas were present. We tested two main hypotheses. H1) Lianas reduce tree seedling survival and growth. H2) The strength of the effect of liana competition varies with tree species identity. To interpret the type of competition that lianas may impose on tree seedlings, we formulated two specific predictions, assuming that hypothesis 1 is true.

Prediction 1: If the response of tree species varies predictably with their shade-tolerance classification, so that shade-tolerant species are less sensitive to liana removal than are partially shade-tolerant species (sensu Kitajima 1994), then liana removal is likely to have the greatest effect on the performance of partially shade-tolerant tree seedlings by increasing light availability. If so, as light in the understory returns to pre-cutting conditions by trees compensating for the loss of liana leaves (M. E. Rodriguez-Ronderos and S. A. Schnitzer, unpublished manuscript), the effect of liana removal may be the result of the short-term increase in light availability, and therefore transient.

Prediction 2: If the response of tree species does not vary in a predictable way with their shade-tolerance classification, then lianas affect tree seedlings via a mechanism other than solely the reduction of light in the understory (e.g., some change in the abiotic environment, belowground competition, or a combination of below- and aboveground competition). Alternatively, if the response of trees to liana removal does not vary with species identity for any of the 14 species, then H2 is not supported, and recent increases in liana abundance should not fundamentally alter tree species diversity or community composition.

\section{Methods \\ Study site}

We conducted the study on Gigante Peninsula, which is part of the Barro Colorado Natural Monument (BCNM, $09^{\circ} 10^{\prime} \mathrm{N}, 79^{\circ} 51^{\prime} \mathrm{W}$ ) in the Republic of Panama. The BCNM is a 5400 -ha protected area of lowland semi-deciduous tropical forest, administered by the Smithsonian Tropical Research Institute. Mean annual precipitation in the area is $2600 \mathrm{~mm}$, with a pronounced dry season from December until late April 
(Windsor 1990, Leigh 1999). The forest on Gigante Peninsula is a mix of early and late secondary, seasonally moist, lowland tropical forest and is located immediately to the south of Barro Colorado Island (BCI) (Schnitzer and Carson 2010, Schnitzer et al. 2014, Álvarez-Cansino et al. 2015). Soils of the Gigante Peninsula are oxisols and alfisols with high nitrogen and phosphorus availability (Cavelier 1992, Yavitt 2000). The climate, geology, vegetation, and ecological characteristics of the forest on the BCNM are described by Croat (1978), Windsor (1990), and Leigh (1999).

\section{Experimental design and measurements}

In 2008, we established $1680 \times 80 \mathrm{~m}$ experimental plots in $\sim 60$-yr-old forest on Gigante Peninsula. We selected plots in relatively flat areas that were not bisected by streams and that had similar forest structure in terms of the density and basal area of trees and lianas. All plots were oriented toward magnetic north. In each plot, we tagged, mapped, measured the diameter, and identified to species all trees $\geq 20 \mathrm{~cm}$ diameter and lianas $\geq 5 \mathrm{~cm}$ diameter, as well as all trees and lianas $\geq 1 \mathrm{~cm}$ diameter within the $60 \times 60 \mathrm{~m}$ center area $(>24000$ trees in all plots, $>9000$ rooted lianas in the control plots).

In April 2011, we cut all of the lianas in eight randomly selected plots, while the remaining eight plots served as unmanipulated controls. We cut all lianas above the soil surface throughout the $80 \times 80 \mathrm{~m}$ area, as well as all lianas that were rooted outside but were growing into the plot. We did not remove lianas from trees because of the risk of damaging tree crowns. Rather, we allowed them to fall from the trees as they decayed. Although the leaves of cut lianas fell within the first week, cut lianas do not die immediately; instead, they tend to produce copious new stems. Thus we monitored the plots and cut re-sprouting liana shoots every 2 months throughout the study to maintain the liana removal treatment (methods follow Schnitzer and Carson 2010, Schnitzer et al. 2014). Liana re-sprouting diminishes with time, and after the first year there were few vigorous new stems. We visited the unmanipulated control plots at the same frequency as the liana removal plots to avoid a researcher visitation effect (e.g., Cahill et al. 2001, Schnitzer et al. 2002).

During July and August 2011, we transplanted 14 replicate seedlings of 14 target tree species (196 seedlings) into a $5 \times 5 \mathrm{~m}$ plot located in the center of each $80 \times 80 \mathrm{~m}$ plot (3136 total tree seedlings across all 16 plots). Seedling plots were placed in the same relative location within each of the 16 main plots (10 $\mathrm{m}$ south of the center of the plot), regardless of the vegetation present; however, we relocated the plots slightly if there was a large tree in the middle of the proposed seedling plot. We did not remove or alter vegetation in the $5 \times 5 \mathrm{~m}$ plots before or after the tree seedlings were transplanted, except to cut liana sprouts when present in the liana-removal plots. Tree seedling species selection was based on differences in shade tolerance (from moderate to highly shade tolerant), adult stature, and leaf phenology (Table 1).

TABLE 1. Description of the 14 tropical tree species used in this study, listed in alphabetic order, with scientific and family names, species code as used in the text.

\begin{tabular}{|c|c|c|c|c|c|c|}
\hline Species & Family & Sp. Code & AS & WD & LP & RST \\
\hline Albizia spp. & Fabaceae & ALB & $10-20$ & 0.50 & SD & PST \\
\hline Anacardium excelsum & Anacardiaceae & ANAE & 40 & 0.41 & $\mathrm{D}$ & PST \\
\hline Bombacopsis quinnata & Bombacaceae & BOMQ & $25-35$ & 0.51 & $\mathrm{D}$ & ST \\
\hline Bursera simaruba & Burseraceae & BURS & $5-20$ & 0.34 & $\mathrm{D}$ & PST \\
\hline Cedrela odorata & Meliaceae & CEDO & 30 & 0.38 & $\mathrm{D}$ & ST \\
\hline Crescentia cujete & Bignoniaceae & CREC & $6-10$ & 0.60 & $\mathrm{E}$ & PST \\
\hline Dalbergia retusa & Leguminosae & DALR & $20-30$ & 0.89 & $\mathrm{D}$ & ST \\
\hline Diphysa americana & Fabaceae & DIPA & $5-15$ & 0.96 & $\mathrm{D}$ & ST \\
\hline Hura crepitans & Euphorbiaceae & HURC & 45 & 0.41 & SD & PST \\
\hline Spondias mombin & Anacardiaceae & SPOM & $10-35$ & 0.41 & SD & PST \\
\hline Sterculia apetala & Sterculiaceae & STEA & 40 & 0.36 & $\mathrm{D}$ & PST \\
\hline Swietenia macrophylla & Meliaceae & SWIM & 50 & 0.54 & $\mathrm{D}$ & PST \\
\hline Tabebuia rosea & Bignoniaceae & TABR & $10-30$ & 0.54 & $\mathrm{D}$ & PST \\
\hline Terminalia amazonia & Combretaceae & TERA & 50 & 0.69 & SD & PST \\
\hline
\end{tabular}

Notes: Adult stature (AS; meters), wood density (WD; g/ $\mathrm{cm}^{3}$ ), leaf phenology (LP; SD = semi-deciduous; D = deciduous; $\mathrm{E}=$ evergreen $)$ and range of shade tolerance $(\mathrm{PST}=$ partially shade-tolerant; $\mathrm{ST}=$ shade-tolerant $)$. Adult stature and woody density values were obtained from Reyes et al. (1992). Shade tolerance classifications (RST) were based on the following sources: Croat (1978), Stevens (1987), Nichols (1994), Cordero and Kanninenc (2002), Hooper et al. (2002), Kitajima (2002), Wishnie et al. (2002), Poorter et al. (2006), Zahawi and Holl (2009), Celis and Jose (2011). 
Seeds were germinated and seedlings grown in small pots in a shaded environment. We transplanted all individuals into the forest understory with a small amount of nursery soil when they were 5 months old. Seedlings were planted in a grid $25 \mathrm{~cm}$ from their nearest neighbor, and each individual was tagged loosely with a unique number. The location of each seedling was assigned randomly in every plot to avoid biases at the species level.

After a four-month establishment period, we quantified seedling mortality monthly from January 2012 until May 2013. We recorded tree seedlings as dead when the seedling was completely missing, or when the seedling was present but appeared to be dead. Data were corrected in the rare cases of apparent resurrection, where a seedling re-sprouted after being recorded as dead. We measured seedling height and counted the number of leaves at the beginning of the dry season (January) and at end of the dry season (May) in 2012 and in 2013. We measured seedling height vertically from the forest floor to the highest apical meristem of the plant.

In May 2013, we harvested all seedlings by cutting the stems immediately below the root collar. Immediately after cutting the seedlings, we put them on ice and transported them the same day to the laboratory for processing. In the laboratory, we separated each plant into leaves and stems. We measured total leaf area and total fresh and dry mass of leaves and stems separately for all seedlings. We oven-dried leaves and stems at $60^{\circ} \mathrm{C}$ for $48 \mathrm{~h}$ (leaves) and $72 \mathrm{~h}$ (stems) prior to weighing to determine dry mass. We recorded leaf area (LA; square millimeters) with a Li-COR LI-3100C leaf area meter (Biosciences, Lincoln, Nebraska, USA), frequently calibrating the area meter by using a sample of known area before measuring. We quantified aboveground biomass (BIOM; total dry aboveground plant mass; grams) and leaf area (LA; total leaf area per individual per species; square centimeters) in all plots to determine the effect that liana removal had on seedling growth. We also measured specific leaf area (SLA; leaf area/dry leaf mass; in square centimeters per gram) among treatments to determine if species changed their leaf construction in response to the presence of lianas.

\section{Data analysis}

Tree seedling survival. -We analyzed survivorship using nonparametric Kaplan-Meier survival distribution functions, which describe the probability that an individual survives longer than a specified period of time. We used nonparametric log-rank tests to test for significant differences in seedling survival probabilities between the liana-removal and control treatments. To determine whether the effect of lianas on tree survival varied with tree species identity, we calculated for each species the proportional survivorship at each census period as the number of individuals that survived between consecutive censuses divided by the total number of individuals alive in the previous census. We then analyzed seedling survival using a linear mixed model for repeated measures, with treatment (liana removal and control) and species identity as fixed factors, and census period as a random effect.

Tree seedling growth.-We quantified the growth of each seedling by calculating the relative growth rate in height $\left(\mathrm{RGR}_{\mathrm{h}}\right.$, centimeters per centimeter per month) using the formula: $\mathrm{RGR}_{\mathrm{h}}=\left[\ln \left(\mathrm{ht}_{1}\right)-\ln (\mathrm{ht})\right] /\left(t_{1}-t_{0}\right)$, where $\mathrm{ht}_{1}$ is the seedling height (centimeters) in a given census, $\mathrm{ht}_{0}$ is the seedling height (centimeters) in the previous census, and $t_{1}-t_{0}$ was the difference in months between sampling census. Since growth was measured on the same plants over time, we analyzed all 14 species together using a linear mixed model for repeated measures to examine the effect of treatment, species identity, and the two-way interactions for $\mathrm{RGR}_{\mathrm{h}}$ and leaf production rate (LPR; leaf per leaf per month). We also compared seedling aboveground biomass (BIOM), leaf area (LA), and specific leaf area (SLA) between control and liana-removal plots using two-way ANOVAs, with treatment and species identity as independent variables, and BIOM, LA, and SLA as dependent variables. Data were $\log _{10}$-transformed before analyses to increase normality and homogeneity of variance when it was necessary to satisfy the assumption of ANOVA. All statistical analyses were conducted with SPSS Statistics 20 (IBM SPSS 2011).

\section{RESULTS}

\section{Effects of lianas on tree seedling survival}

After 17 months, survival of tree seedlings was $75 \%$ higher in liana removal than in control plots, demonstrating that liana removal significantly increased tree seedling survival (Kaplan-Meier test, $\chi^{2}=21.65, P<0.001$; Fig. 1). Tree seedling survival was higher in the liana-removal plots compared to control plots for 13 species, and only Swietenia macrophylla survived slightly (but not significantly) better in control plots (Appendix S1). The lack of a significant treatment $\times$ species interaction for seedling survivorship indicated that all species responded to liana competition in a similar manner (repeated measures ANOVA, $F=0.54$, $\mathrm{df}=13, P=0.90$ ). Seedling mortality appeared to vary with season and was $61 \%$ higher in the control plots compared to the lianaremoval plots during the first dry season, 33\% higher in the second dry season, and $22 \%$ higher during the intervening wet season (Fig. 2); however, differences in seedling mortality during the wet season and the second dry season were not statistically significant. 


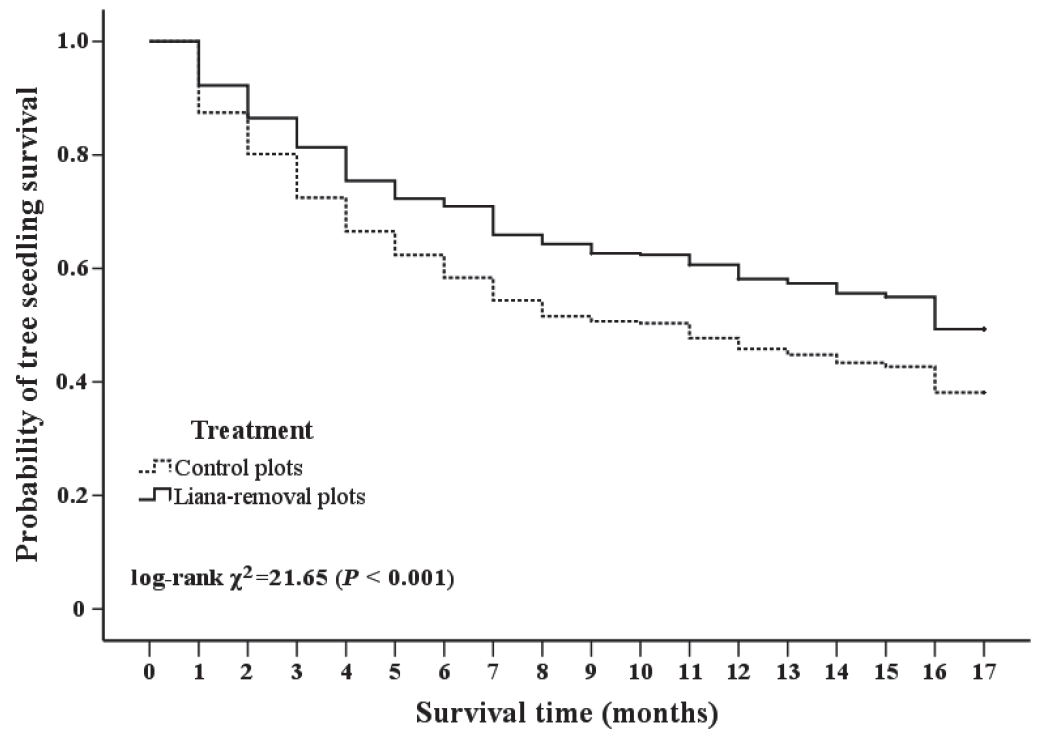

FIG. 1. Kaplan-Meier survival function for tree seedlings in $1680 \times 80 \mathrm{~m}$ liana removal and control plots on Gigante Peninsula, Panama throughout the study period (January 2012-May 2013). Tree seedling survival was significantly lower in the presence of lianas than in liana-free plots, demonstrating that lianas reduce tree seedling survival in the forest understory.

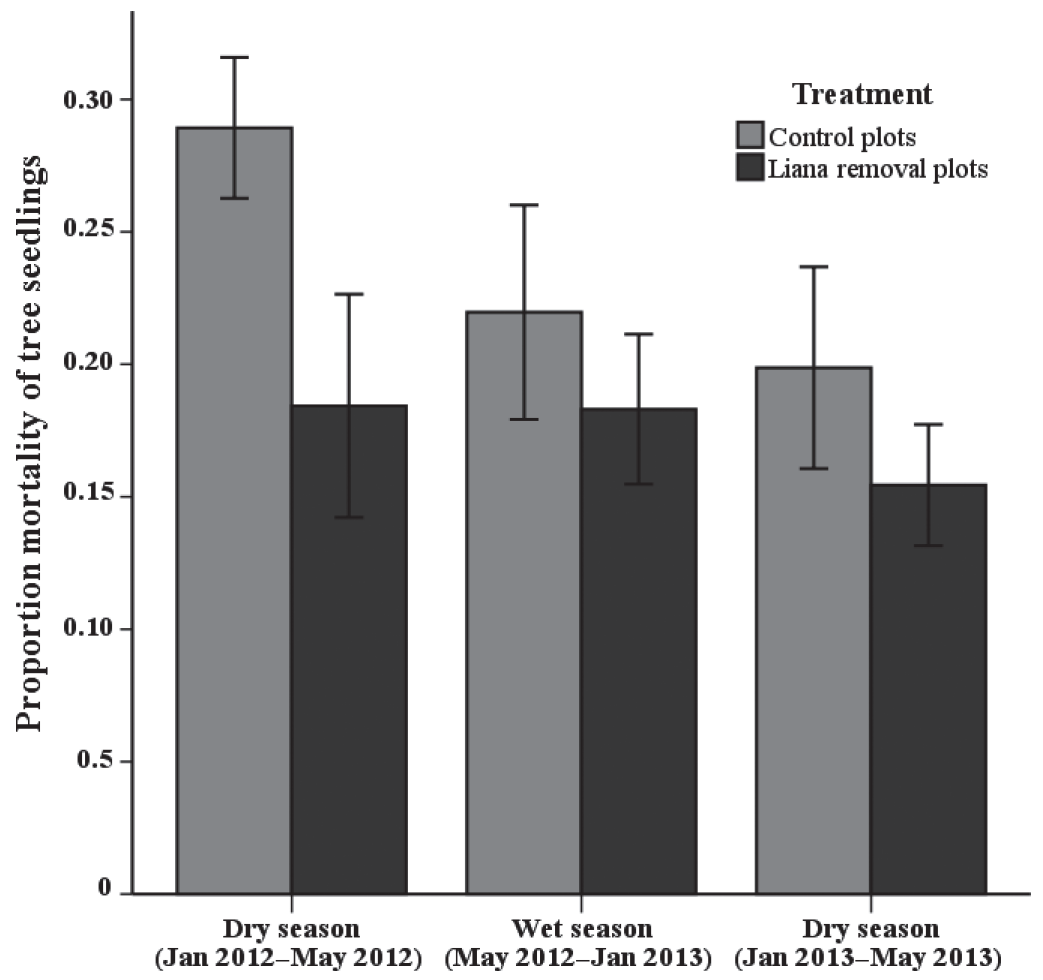

FIG. 2. Mean proportional mortality of tree seedlings over subsequent censuses in $1680 \times 80 \mathrm{~m}$ liana-removal and control plots on Gigante Peninsula, Panama. Seedling mortality was significantly greater in the presence of lianas than in plots where lianas had been removed. The effect of lianas on tree seedling mortality was strongest during the dry seasons, particularly in the first year. Error bars represent \pm 1 SE. 
Effects of lianas on tree seedling growth, biomass, and leaf area

The presence of lianas significantly reduced tree seedling relative height growth, aboveground biomass, and leaf area over the 2-yr period. During the initial dry season, mean tree $\mathrm{RGR}_{\mathrm{h}}$ was $300 \%$ higher in liana-removal plots compared to control plots (Table 2, Fig. 3). These differences became smaller during the subsequent wet and dry seasons as the plants became more established (Fig. 3). Nonetheless, mean seedling aboveground biomass at the final harvest was $>100 \%$ greater in liana removal than in control plots $(2.26 \pm 0.15 \mathrm{~g}$ vs. $1.06 \pm 0.24 \mathrm{~g} ;$ ANOVA, $F=20.12$, df $=1, P<0.001)$. Mean seedling leaf area was nearly $100 \%$ greater in the liana-removal plots compared to control plots $\left(2.51 \pm 0.18 \mathrm{~cm}^{2}, 1.36 \pm 0.28 \mathrm{~cm}^{2}\right.$; ANOVA, $F=20.12$, df $=1, P=0.04)$. Specific leaf area and leaf production rate did not differ between treatments (ANOVA, $F=2.22$, $\mathrm{df}=1, P=4.15$ and Table 2, respectively). Nearly all species exhibited greater height growth in the liana removal plots than in control plots (Appendix S2), and the lack of a significant treatment by tree species interaction for $\mathrm{RGR}_{\mathrm{h}}$ (Table 2) indicated that all species responded similarly.

\section{DisCUSSION}

Our findings demonstrate that lianas compete intensely with tree seedlings, significantly reducing their growth and survival in the forest understory. Over the study period, tree seedlings growing in the absence of lianas had significantly higher survival ( $75 \%$ higher), height growth ( $300 \%$ higher), aboveground biomass $(\sim 100 \%$ higher $)$, and leaf area $(\sim 100 \%$ higher $)$ than did seedlings growing in the presence of lianas. These findings support the hypothesis that lianas compete intensely with tree seedlings, and confirm the results of previous liana-removal experiments that examined a range of tree life history stages (seedling, sapling, and adult; Pérez-Salicrup 2001, Schnitzer et al. 2005, Peña-Claros et al. 2008, Toledo-Aceves and Swaine 2008, Schnitzer and Carson 2010, Tobin et al. 2012, Álvarez-Cansino et al. 2015, Toledo-Aceves 2015).

Table 2. Result of linear mixed model for repeated measures analysis for the effects of treatment, species, and interaction on the relative height growth rate of tree seedlings $\left(\mathrm{RGR}_{\mathrm{h}}\right)$ and leaf production rate (LPR) for all 14 species in Gigante Peninsula, Panama.

\begin{tabular}{lcccccc}
\hline \hline Factors & \multicolumn{3}{c}{ RGR $_{\mathrm{h}}$} & \multicolumn{3}{c}{ LPR } \\
& $\mathrm{df}$ & $F$ & $P$ & $\mathrm{df}$ & $F$ & $P$ \\
\hline Intercept & 1 & 0.13 & 0.72 & 1 & 169.61 & 0.00 \\
Treatment & 1 & 4.76 & $\mathbf{0 . 0 3}$ & 1 & 0.12 & 0.73 \\
Species & 13 & 4.25 & $\mathbf{0 . 0 0}$ & 13 & 28.29 & $\mathbf{0 . 0 0}$ \\
Treatment $\times$ species & 13 & 0.82 & 0.64 & 13 & 1.55 & 0.09 \\
\hline
\end{tabular}

Our data do not support the hypothesis that the negative effect of lianas varies with species identity. The 14 tree species in our study differed significantly in their rates of survival, growth, and leaf production in the understory (Table 2), which would be expected based on their varying life history characteristics. The species vary fivefold in maximum canopy height as adults $(10-50 \mathrm{~m})$, nearly threefold in wood density $\left(0.36-0.96 \mathrm{~g} / \mathrm{cm}^{3}\right)$, and they differ in shade tolerance (partially shade tolerant vs. shade tolerant (Table 1). Despite these large differences, however, all of the species responded similarly to the liana removal treatment (i.e., there were no significant treatment by species interactions; Table 2), indicating that lianas did not have a species-specific effect on tree seedling growth or survival.

Previous experimental studies on the species-specific response of trees to liana competition have yielded mixed results. For example, several studies examined the effects of lianas on seedlings of three tree species, and all reported that one tree species differed from the response of the other two (Pérez-Salicrup 2001, Toledo-Aceves and Swaine 2008, Wright et al. 2015). By contrast, Schnitzer et al. (2005) removed lianas from tree saplings and found that lianas competed intensely with all three tree species examined, reducing sapling growth by more than five-fold after $2 \mathrm{yr}$. The study by Wright et al. (2015) was unique in that it used a target-tree approach in which they removed lianas from around a single target tree and examined the response of planted seedlings below. The target tree approach may have resulted in a much more diffuse effect of liana removal, because lianas can deploy their leaves in the crowns of multiple trees, and thus only a portion of the lianas leaves may have been in the canopy of the target-tree (see Discussion in Wright et al. 2015). By contrast, Álvarez-Cansino et al. (2015) examined sap velocity of replicate adults of seven canopy tree species in a subset of six of the same $80 \times 80 \mathrm{~m}$ experimental plots used in the current study (three liana removal and three control) and found that the negative effect of lianas did not vary with tree species identity. Our study differs from previous ones in that we used many more species, all with high replication, and we conducted the study within the context of a large-scale, community-level liana removal experiment that integrated the effects of lianas across a large area. Collectively, these studies suggest that lianas have a generally negative effect on tree species, regardless of their identity and ontogenetic stage.

The negative effect of lianas on tree seedlings in this study was not caused by direct physical interactions such as mechanical loading, abrasion, and strangulation (Vleut and Pérez-Salicrup 2005) because none of the seedlings hosted lianas. Instead, the effect of liana removal on tree seedling growth and survival could have been due to the increase in light in the 

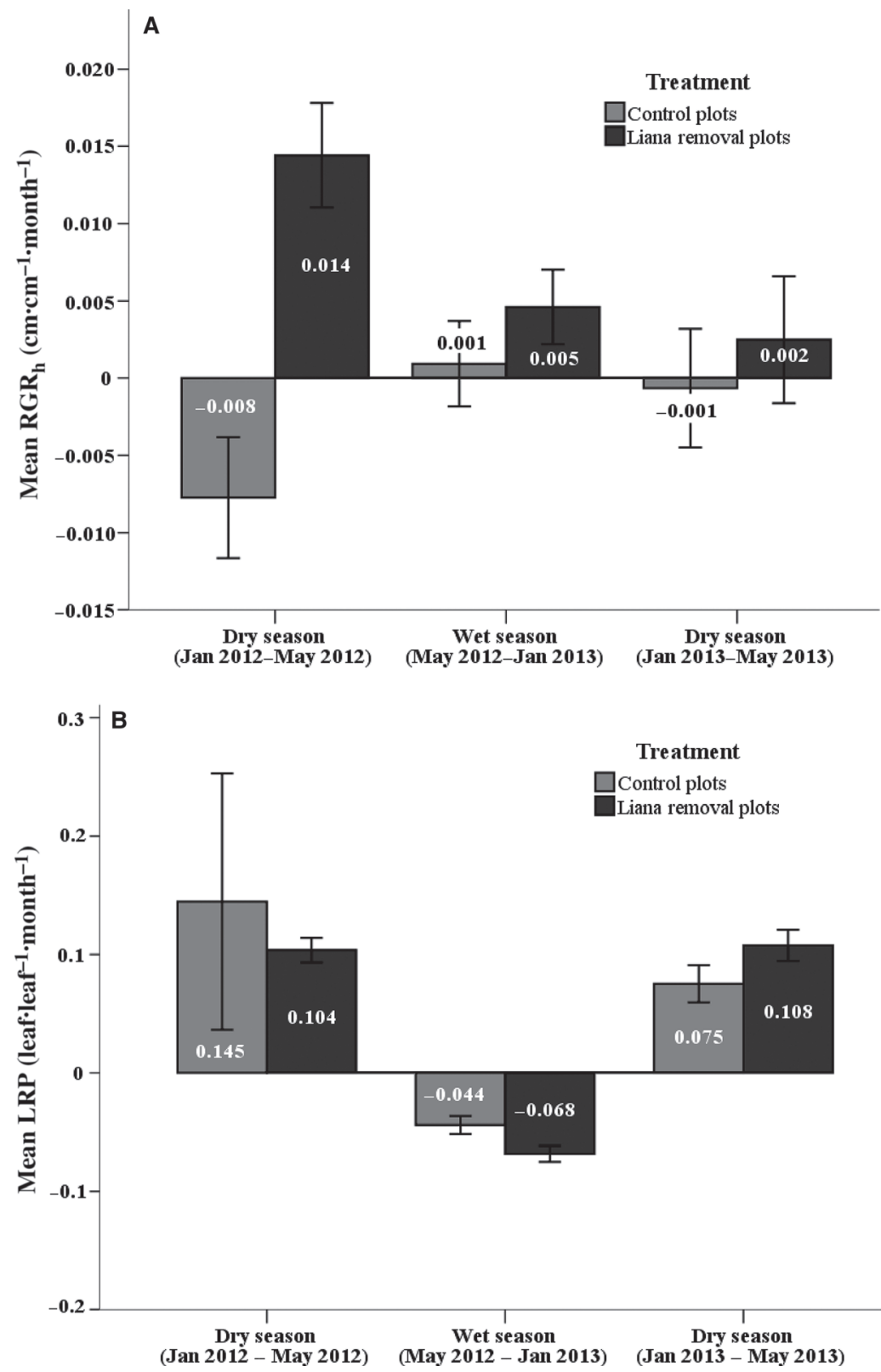

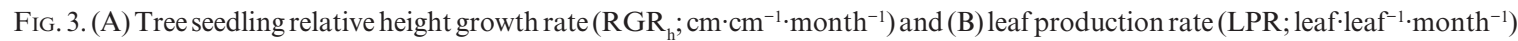
in $1680 \times 80 \mathrm{~m}$ liana removal and control plots on Gigante Peninsula, Panama. Mean RGR decreased significantly in the presence of lianas, and the effect was particularly strong during the first dry season. Mean LPR did not differ between treatments. Error bars represent $\pm 1 \mathrm{SE}$, and the values inside the bars represent the means.

understory, which benefited all tree species in the study. Light is a major environmental factor that limits survival and growth of tree seedlings in tropical forests. In general, $<2 \%$ of the radiation above the canopy reaches the forest floor (Kitajima 1994, Clark et al. 1996). Once lianas become established in the crown of their host tree, the liana foliage blankets the host's leaves and branches, which significantly reduces light availability (liana leaves displace tree leaves on a 1-to-1 mass basis; Kira and Ogawa 1971). Lianas may also effectively cover portions of the space between tree crowns, thus further attenuating light in the understory. In our study plots, mean plot level leaf area index (LAI) decreased by $20 \% 1 \mathrm{yr}$ after cutting lianas, compared to the control plots (M. E. Rodriguez and S. A. Schnitzer, unpublished data). By March 2013, $2 \mathrm{yr}$ after cutting lianas, mean LAI in the liana-removal and control plots was much more similar (5.44 vs. 5.96), and there was no longer a significant LAI treatment effect (although the mean light level was still 
nearly $10 \%$ higher in the liana removal plots [M. E. Rodriguez and S. A. Schnitzer, unpublished data]). Thus, the increased amount of light in the liana-removal plots may have been responsible for greater tree seedling growth and survival.

The increase in light alone, however, may not have been responsible for the negative effect of lianas on tree seedlings. If light availability alone had been the driving factor for the strong response in tree seedling growth and mortality following liana removal, we would have expected seedlings to respond in a manner consistent with their shade tolerance classification. That is, partially shade-tolerant species would have grown and survived more, on average, than shade-tolerant species in the liana-removal plots compared to the controls (Kitajima 1994). This prediction, however, was not supported. Seedling growth and survival was consistently higher in liana-removal plots for nearly all tree species, and neither growth nor survival was higher for partially shade-tolerant species than for shadetolerant species (Appendices $\mathrm{S} 1$ and $\mathrm{S} 2$ ).

The lack of a distinct response between the shadetolerant and partially shade-tolerant species indicates that factors other than light may have contributed to tree seedling responses to liana removal. One possibility is that lianas are competing intensely with trees for belowground resources. There is compelling evidence for intense belowground competition between lianas and trees, particularly in tropical forests that experience seasonal droughts (e.g., Lewis and Tanner 2000, Schnitzer et al. 2005, Tanner and Barberis 2007, Chen et al. 2008, Toledo-Aceves and Swaine 2008, Toledo-Aceves 2015). Lianas appear to have welldeveloped root and vascular systems, which presumably allow them to take up water and nutrients from the forest floor and transport them efficiently to their crowns (Pérez-Salicrup and Barker 2000, Andrade et al. 2005, Schnitzer 2005). For example, sap flow velocity of adult canopy tree species on Gigante Peninsula increased significantly in plots where lianas were cut compared to control plots, and this effect was particularly strong during the dry season (Tobin et al. 2012, Álvarez-Cansino et al. 2015). Wright et al. (2015) found that lianas had a particularly strong negative effect on seedlings of Dipteryx oleifera during the dry season compared to the wet season. Strong belowground competition from lianas is consistent with studies demonstrating that lianas are able to access water and grow much faster than trees during seasonal droughts (e.g., Schnitzer 2005, Cai et al. 2009, Chen et al. 2015). In our study, tree seedling survival during the first and second dry seasons was $61 \%$ and $33 \%$ higher in the liana removal plots compared to the control plots, and only $22 \%$ higher during the intervening wet season (Fig. 3), a finding that is consistent with intense belowground competition from lianas during the dry season. As light levels in the liana removal and control plots converge, future studies in this ongoing, long-term experiment will allow us to examine the unique competitive effect of lianas on tree seedlings independent of the effect of light.

Because of the unique competitive ability of lianas, we believe that removing lianas is different than removing a similar amount of tree biomass. In a previous study on Gigante Peninsula, we found that cutting lianas had a large and significantly negative effect on target trees, but that cutting the same amount of biomass of nearby trees had little effect on target trees (Tobin et al. 2012). Furthermore, the competitive release from liana cutting can last many years, even after the tree community has had sufficient time to recover from liana removal (Schnitzer and Carson 2010, Schnitzer et al. 2014). The unique competitive ability of lianas may be attributable to their strategy of allocating more energy to resource capture (root and stem elongation and leaf production) rather than structure (self-supporting stems or anchoring roots; Wyka et al. 2013), as well as their ability to reach the forest canopy and compete with canopy trees at very small stem diameters (Kurzel et al. 2006). This strategy appears to allow lianas to compete intensely at a fraction of the biomass investment compared to trees (van der Heijden et al. 2013, Schnitzer et al. 2014).

In summary, lianas compete intensely with trees and appear to limit tree seedling regeneration, likely through a combination of above- and belowground competition. However, we found no evidence to support the claim that the competitive effect of lianas varies with tree species identity. Our findings are consistent with strong negative effects of lianas on tree seedlings, saplings, and adults, regardless of tree species identity. Thus, the reported increase in liana density and biomass in many neotropical forests (Schnitzer and Bongers 2011, Schnitzer 2015) may depress the regeneration and vitality of many tropical tree species, but there is currently little evidence that increasing lianas will significantly alter tree species relative abundance or community composition.

\section{ACKNOWLEDGMENTS}

We thank Guadalupe Alvarado, Evelyn Sánchez, Salomé Pérez, Oldemar Valdés, Abelino Valdés, Severino Valdés, and Boris Bernal for valuable assistance in the field. We are grateful to Nick Rowe, Deborah Clark, and especially Natalia Norden, who made substantive comments on several versions of the manuscript. Financial support was provided by NSF-DEB 0845071 and NSF-DEB 1019436 (to S. A. Schnitzer), and NSF DEB-1019441 (to J. S. Powers).

\section{Literature Cited}

Álvarez-Cansino, L., S. A. Schnitzer, J. P. Reid, and J. S. Powers. 2015. Liana competition with tropical trees varies with seasonal rainfall and soil moisture, but not tree species identity. Ecology 96:39-45. 
Andrade, J. L., F. C. Meinzer, G. Goldstein, and S. A. Schnitzer. 2005. Water uptake and transport in lianas and co-occurring trees of a seasonally dry tropical forest. Trees 19:282-289.

Beer, C., et al. 2010. Terrestrial gross carbon dioxide uptake: global distribution and covariation with climate. Science 329:834-838.

Bonan, G. B. 2008. Forests and climate change: forcings, feedbacks, and the climate benefits of forests. Science 320:1444 1449.

Cahill, J. F., J. P. Castelli, and B. B. Casper. 2001. The herbivore uncertainty principle: visiting plants can alter herbivory. Ecology 82:307-312.

Cai, Z. Q., S. A. Schnitzer, and F. Bongers. 2009. Seasonal differences in leaf-level physiology give lianas a competitive advantage over trees in a tropical forest. Oecologia 161:25-33.

Carsten, L. D., F. E. Juola, T. D. Male, and S. Cherry. 2002. Host associations of liana in a south-east Queensland rain forest. Journal of Tropical Ecology 18:107-120.

Cavelier, J. 1992. Fine-root biomass and soil properties in a semideciduous and a lower montane rain forest in Panama. Plant and Soil 142:187-201.

Celis, G., and S. Jose. 2011. Restoring abandoned pasture land with native tree species in Costa Rica: effects of exotic grass competition and light. Forest Ecology and Management 261:1598-1604.

Chen, Y.-J., F. Bongers, K.-F. Cao, and Z. Q. Cai. 2008. Above and belowground competition in high and low irradiance: tree seedling responses to a competing liana Byttneria grandifolia. Journal of Tropical Ecology 24:517-524.

Chen, Y.-J., K.-F. Cao, S. A. Schnitzer, Z.-X. Fan, J.-L. Zhang, and F. Bongers. 2015. Water-use advantage of lianas over trees in seasonal tropical forests. New Phytologist 205:128-136.

Chittibabu, C. V., and N. Parthasarathy. 2001. Liana diversity and host relationships in a tropical evergreen forest in the Indian Eastern Ghats. Ecological Research 16:519-529.

Clark, D. B., and D. A. Clark. 1990. Distribution and effects on tree growth of lianas and woody hemiepiphytes in a Costa Rican tropical wet forest. Journal of Tropical Ecology 6:321-331.

Clark, D. B., D. A. Clark, P. M. Rich, S. Weiss, and S. F. Oberbauer. 1996. Landscape-scale evaluation of understory light and canopy structure: methods and application in a neotropical lowland rain forest. Canadian Journal of Research 26:747-757.

Cordero, L. D. P., and M. Kanninenc. 2002. Wood specific gravity and aboveground biomass of Bombacopsis quinata plantations in Costa Rica. Forest Ecology and Management 165:1-9.

Croat, T. B. 1978. Flora of Barro Colorado Island. Stanford University Press, Stanford, California, USA.

Gibbs, H. K., S. Brown, J. O. Niles, and J. A. Foley. 2007. Monitoring and estimating tropical forest carbon stocks: making REDD a reality. Environmental Research Letters 2:1-13.

Hooper, E., R. Condit, and P. Legendre. 2002. Responses of 20 native tree species to reforestation strategies for abandoned farmland in Panama. Ecological Applications 12:1626-1641.

IBM SPSS 2011. IBM SPSS Statistics 20. IBM SPSS, Chicago, Illinois, USA.

Ingwell, L. L., S. J. Wright, K. K. Becklund, S. P. Hubbell, and S. A. Schnitzer. 2010. The impact of lianas on 10 years of tree growth and mortality on Barro Colorado Island, Panama. Journal of Ecology 98:879-887.

Kainer, A. K., L. H. O. Wadt, D. A. P. Gomes-Silva, and M. Capanu. 2006. Liana loads and their association with Bertholletia excelsa fruit and nut production, diameter growth and crown attributes. Journal of Tropical Ecology 22:147-154.

Kira, T., and H. Ogawa. 1971. Assessment of primary production in tropical and equatorial forests. Pages 309-321 in P. Duvigneaud, editor. Productivity of forest ecosystems. UNESCO, Paris, France.
Kitajima, K. 1994. Relative importance of photosynthetic traits and allocation patterns as correlates of seedling shade tolerance of 13 tropical trees. Oecologia 98:419-428.

Kitajima, K. 2002. Do shade-tolerant tropical tree seedlings depend longer on seed reserves?. Functional growth analysis of three Bignoniaceae species. Functional Ecology 16:433-444.

Kurzel, B. P., S. A. Schnitzer, and W. P. Carson. 2006. Predicting liana crown location from stem diameter in three Panamanian lowland forests. Biotropica 38:262-266.

Laurance, S. G. W., W. F. Laurance, H. E. M. Nascimento, A. Andrade, P. M. Fearnside, E. R. G. Rebello, and R. Condit. 2009. Long-term variation in Amazon forest dynamics. Journal of Vegetation Science 20:323-333.

Leigh, E. G. 1999. Tropical forest ecology: a view from Barro Colorado Island. Oxford University Press, Oxford, UK.

Lewis, S. L. and E. V. Tanner. 2000. Effects of above and belowground competition on growth and survival of rain forest tree seedlings. Ecology 81:2525-2538.

Nichols, J. D. 1994. Terminalia amazonia development of a native species for reforestation and agroforestry. Commonwealth Forestry Review 73:9-13.

Pan, Y., et al. 2011. A large and persistent carbon sink in the world's forests. Science 333:988-993.

Peña-Claros, M., E. M. Petersa, M. J. Justiniano, F. Bongers, G. M. Blatea, T. S. Fredericksen, and F. E. Putz. 2008. Regeneration of commercial tree species following silvicultural treatments in a moist tropical forest. Forest Ecology and Management 255:1283-1293.

Pérez-Salicrup, D. R. 2001. Effect of liana cutting on tree regeneration in a liana forest in Amazonian Bolivia. Ecology 82:389-396.

Pérez-Salicrup, D. R., and M. G. Barker. 2000. Effect of liana cutting on water potential and growth of adult Senna multijuga (Caesalpinioideae) trees in a Bolivian tropical forest. Oecologia 124:469-475.

Phillips, O. L., et al. 2002. Increasing dominance of large lianas in Amazonian forests. Nature 418:770-774.

Poorter, L., L. Bongers, and F. Bongers. 2006. Architecture of 54 moist-forest tree species: traits, trade-offs, and functional groups. Ecology 87:1289-1301.

Putz, F. E. 1984. How trees avoid and shed lianas. Biotropica 16:19-23.

Reyes, G., S. Brown, J. Chapman, and A. E. Lugo. 1992. Wood densities of tropical tree species. USDA Forest Service General Technical Report S0-88. Southern Forest Experiment Station, New Orleans, Louisiana, USA.

Schnitzer, S. A. 2005. A mechanistic explanation for global patterns of liana abundance and distribution. American Naturalist 166:262-276.

Schnitzer, S. A. 2015. Increasing liana abundance and biomass in neotropical forests: causes and consequences. Pages 451-454 in S. A. Schnitzer, F. Bongers, R. J. Burnham, and F. E. Putz, editors. The ecology of lianas. Wiley-Blackwell, Oxford, UK.

Schnitzer, S. A., and F. Bongers. 2002. The ecology of lianas and their role in forests. Trends in Ecology and Evolution 17:223-230.

Schnitzer, S. A., and F. Bongers. 2011. Increasing liana abundance and biomass in tropical forests: emerging patterns and putative mechanisms. Ecology Letters 14:397-406.

Schnitzer, S. A., and W. P. Carson. 2010. Lianas suppress tree regeneration and diversity in treefall gaps. Ecology Letters 13:849-857.

Schnitzer, S. A., J. W. Dalling, and W. P. Carson. 2000. The impact of lianas on tree regeneration in tropical forest canopy gaps: evidence for an alternative pathway of gap-phase regeneration. Journal of Ecology 88:655-666.

Schnitzer, S. A., P. B. Reich, B. Bergner, and W. P. Carson. 2002. Herbivore and pathogen damage on grassland and woodland 
plants: a test of the Herbivore Uncertainty Principle. Ecology Letters 5:531-539.

Schnitzer, S. A., M. Kuzee, and F. Bongers. 2005. Disentangling above- and below-ground competition between lianas and trees in a tropical forest. Journal of Ecology 93:1115-1125.

Schnitzer, S. A., F. Bongers, and S. J. Wright. 2011. Community and ecosystem ramifications of increasing lianas in neotropical forests. Plant Signaling and Behavior 6:598-600.

Schnitzer, S. A., G. M. F. van der Heijden, J. Mascaro, and W. P. Carson. 2014. Lianas reduce biomass accumulation in a tropical forest. Ecology 95:3008-3017.

Stevens, G. C. 1987. Lianas as structural parasites: the Bursera simaruba example. Ecology 68:77-81.

Tanner, E. V. J., and I. M. Barberis. 2007. Trenching increased growth and irrigation increased survival of tree seedlings in the understory of a semi-evergreen rain forest in Panama. Journal of Tropical Ecology 23:257-268.

Tobin, M. F., A. J. Wright, S. A. Mangan, and S. A. Schnitzer 2012. Lianas have a greater competitive effect than trees of similar biomass on tropical canopy trees. Ecosphere 3:1-11.

Toledo-Aceves, T. 2015. Above- and belowground competition between lianas and trees. Pages 149-163 in S. A. Schnitzer, F. Bongers, R. J. Burnham and F. E. Putz, eds. The ecology of lianas. Wiley-Blackwell, Oxford, UK.

Toledo-Aceves, T., and M. D. Swaine. 2008. Effect of lianas on tree regeneration in gaps and forest understorey in a tropical forest in Ghana. Journal of Vegetation Science 19: $717-728$.

van der Heijden, G. M. F., and O. L. Phillips. 2009. Liana infestation impacts tree growth in a lowland tropical moist forest. Biogeosciences 6:2217-2226.

van der Heijden, G. M. F., J. R. Healy, and O. L. Phillips. 2008. Infestation of trees by lianas in a tropical forest in Amazonian Peru. Journal of Vegetation Science 19:747-756. van der Heijden, G. M. F., S. A. Schnitzer, J. S. Powers, and O. L. Phillips. 2013. Liana impacts on carbon cycling, storage and sequestration in tropical forests. Biotropica 45:682-692.

Vleut, I., and D. R. Pérez-Salicrup. 2005. Lianas and their supporting plants in the understorey at Los Tuxtlas, Mexico. Journal of Tropical Ecology 21:577-580.

Windsor, D. M. 1990. Climate and moisture variability in a tropical forest: long-term records from Barro Colorado Island, Panama. Smithsonian Contributions to the Earth Sciences 29:1-145.

Wishnie, M. H., J. Deago, A. Sautu, and E. Mariscal. 2002. Viability of three native tree species for reforestation in riparian areas within the Panama Canal Watershed, Republic of Panama: Second Annual Report. RORENA working paper ECO-04-03-En. Instituo Smithsonian de Investigaciones Tropicales, Balboa, Ancon, Panama.

Wright, S. J. 2005. Tropical forests in a changing environment. Trends in Ecology and Evolution 20:553-560.

Wright, S. J. 2010. The future of tropical forests. Pages 1-27 in The year in ecology and conservation biology. Volume 1195. Annals of the New York Academy of Sciences. Wiley-Blackwell, New York, New York, USA.

Wright, A. J., M. J. Tobin, S. A. Mangan, and S. A. Schnitzer. 2015. Unique competitive effects of lianas and trees in a tropical forest understory. Oecologia 177:561-569.

Wyka, T. P., J. Oleksyn, P. Karolewski, and S. A. Schnitzer. 2013. Phenotypic correlates of the lianescent growth form-a review. Annals of Botany 112:1667-1681.

Yavitt, J. B. 2000. Nutrient dynamics of soil derived from different parent material on Barro Colorado Island, Panama. Biotropica 32:198-207.

Zahawi, R. A., and K. D. Holl. 2009. Comparing the performance of tree stakes and seedlings to restore abandoned tropical pastures. Restoration Ecology 17:854-864.

\section{SUPPORTING INFORMATION}

Additional supporting information may be found in the online version of this article at http://onlinelibrary.wiley.com/ doi/10.1890/14-2261.1/suppinfo 